\title{
Relação entre insegurança alimentar e frequência do consumo da alimentação escolar em crianças matriculadas em escolas públicas de Viçosa, MG
}

Naruna Pereira Rocha, luana Cupertino Milagres, Ana Paula Pereira Castro, Fernanda Martins de Albuquerque, Mariana de Santis Filgueiras, Juliana Farias de Novaes

\begin{abstract}
Resumo
A vivência da situação de insegurança alimentar e nutricional consiste em violação do Direito Humano à Alimentação Adequada. Alguns Programas públicos como o Programa Nacional de Alimentação escolar (PNAE) atuam para reduzir a vulnerabilidade do seu público alvo (escolares) com a implementação de ações que forneçam uma alimentação adequada e saudável, com melhoria do estado nutricional e perpetuação de bons hábitos alimentares aos escolares e em toda a sua família. A alimentação ofertada na escola muitas vezes pode ser a única refeição completa que os alunos em vulnerabilidade social podem ter acesso. Relacionar as prevalências de insegurança alimentar com a proporção de consumo da alimentação escolar em crianças matriculadas em escolas públicas. Trata-se de um estudo transversal realizado com 268 escolares de 8 e 9 anos da rede pública de ensino. Foram realizadas entrevistas sobre a alimentação escolar por meio de questionários semiestruturados com as crianças e os pais/responsáveis. A situação de insegurança alimentar foi avaliada pela Escala Brasileira de Insegurança Alimentar (EBIA). A análise estatística foi realizada no software Stata versão 13.0, sendo considerado o nível de significância estatística a probabilidade inferior a 5\%. Este estudo foi aprovado pelo Comitê de Ética em Pesquisa com Seres Humanos da Universidade Federal de Viçosa. Altas prevalências de insegurança alimentar foram encontradas nas famílias dos escolares $(57,84 \%)$. Não houve diferenças entre a frequência do consumo da alimentação escolar de acordo com o sexo da criança $(\mathrm{p}=0.052)$. Entretanto, diferenças entre o consumo da alimentação nas escolas municipais das estaduais foram encontradas $(\mathrm{p}=0.004)$. O maior consumo da alimentação escolar esteve associado à situação de insegurança alimentar das crianças ( $\beta=6.06$; IC95\%: 3.74-8.37, $\mathrm{p}=0.008$ ). Entre os escolares, $22.2 \%$ relataram a falta da alimentação escolar em dias letivos. A insegurança alimentar acometeu mais da metade das famílias das crianças matriculadas em escolas públicas. As crianças em situação de insegurança alimentar apresentaram maior consumo da alimentação escolar e relataram ausência da oferta desta alimentação em alguns dias letivos. Esse resultado demonstra a vulnerabilidade social que essas crianças se encontram. Nesse aspecto, o ambiente escolar atua como importante meio na oferta e garantia de uma alimentação adequada e saudável por meio do PNAE. O monitoramento constante deste Programa é importante para que a ausência da oferta da alimentação escolar nos dias letivos não ocorra.
\end{abstract}

Descritores: Programa Nacional de Alimentação Escolar; Insegurança alimentar e nutricional; Escolares. 